\title{
Team-taught course simultaneously impacts the improvement of science and social literacy
}

\author{
www.mrs.org/imos
}

$\mathrm{D}$ id you know that aluminum was once such a coveted material that Napoléon III had a cutlery service made of it, and a pure aluminum cap first graced the top of the Washington Monument in Washington, DC? Or that Earl Tupper's invention of new containers using what he called Poly T (also known as Tupperware) was going nowhere quickly until Brownie Wise identified its trademark "burp"? Or that residents in the Neolithic settlement of Çatalhöyük (in Turkey) used the same material (clay) for building, cooking, religious rituals, and burying their dead? The history of humankind is a story of the interrelationships between materials and social life. Entire civilizations are described with reference to materials: clay, iron, bronze, steel, and silicon. But our discoveries of materials do not define us. Rather, it is

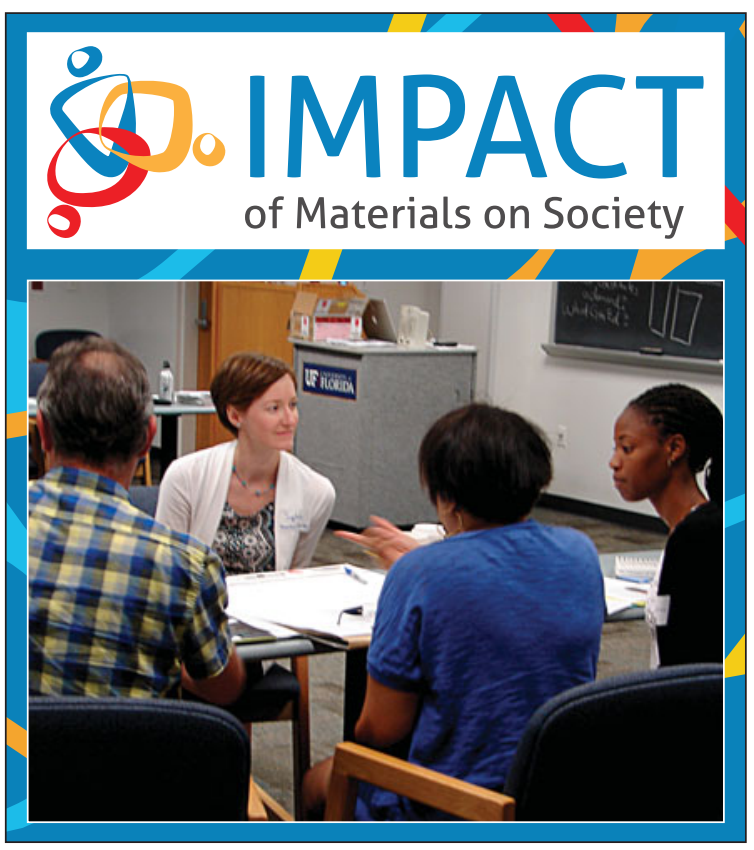

Professors Ken Sassaman, Sophia Acord, and Mary Ann Eaverly discuss the development of new curriculum materials with Danessa Jerome, an engineering student and IMOS course alumni, during a developmental workshop at the University of Florida. how humans have chosen to use and define materials that shape our world.

The Impact of Materials on Society Subcommittee (IMOS) of the Materials Research Society has partnered with faculty from engineering, liberal arts and sciences, and education at the University of Florida to develop an introductory level college course that explores this intersection between materials science and society by bringing lessons from past materials innovations into conversation with cutting-edge materials discoveries. This collaborative, interdisciplinary, project-based course teaches students that engineering shapes, and is shaped by, social and cultural variables, and that a career in engineering is not just about math and science, but also about social problem solving. In particular, this project reveals how different professions and disciplines are connected in the discovery, invention, and application of materials innovations.

"We need technically literate social scientists and humanists, just like we need socially and culturally literate scientists and engineers. In order to solve today's most urgent problems and build a better future, we need to combine multiple literacies and be able to translate between them," said Sophia Acord, Acting Director of the Center for the Humanities and the Public Sphere, University of Florida.

By targeting this course at first-semester college students in two- and four-year institutions, it enables them to draw connections between their general education requirements and core materials science and engineering curricula throughout their undergraduate careers. The lessons introduced in the course are also directly relevant to curricula in sustainability, entrepreneurship, critical thinking, and creative thinking. The goals of this course are to

- enable materials science and engineering students to obtain the broad education necessary to understand the impact of engineering solutions in a global, economic, environmental, and societal context;

- change the perception of materials science and engineering by exposing students in any major to the role, values, and importance of engineering; and

- give students in any major competency in basic materials science and engineering principles.

There are no prerequisites for this course, so freshman in engineering and all other fields can enroll. And the course's grounding in materials gives it a tactile feel that students can explore physically through their daily lives and environment. Kevin Jones, a professor in the Department of Materials Science and Engineering at the University of Florida, and the course's lead instructor, said the course is very modular - each week focuses on a different material and a different social concept applied to that material. "The goal is to introduce these together and then to introduce the students to a future material so that they can learn to apply the social principle, for example entanglement, to this new material," said Jones. In this way, students learn core materials science principles alongside core social and cultural principles to understand the basic tenets of scientific development and social change. 
University of Florida faculty from a range of departments (Anthropology, Classics, History, English, and Sociology) developed weekly instructional materials and assessments. Their humanities perspectives provide the groundwork for helping students to see how the attachments that humans make to materials influence the trajectory of social change. Lessons include basic principles of materials classes and properties-structure-processing

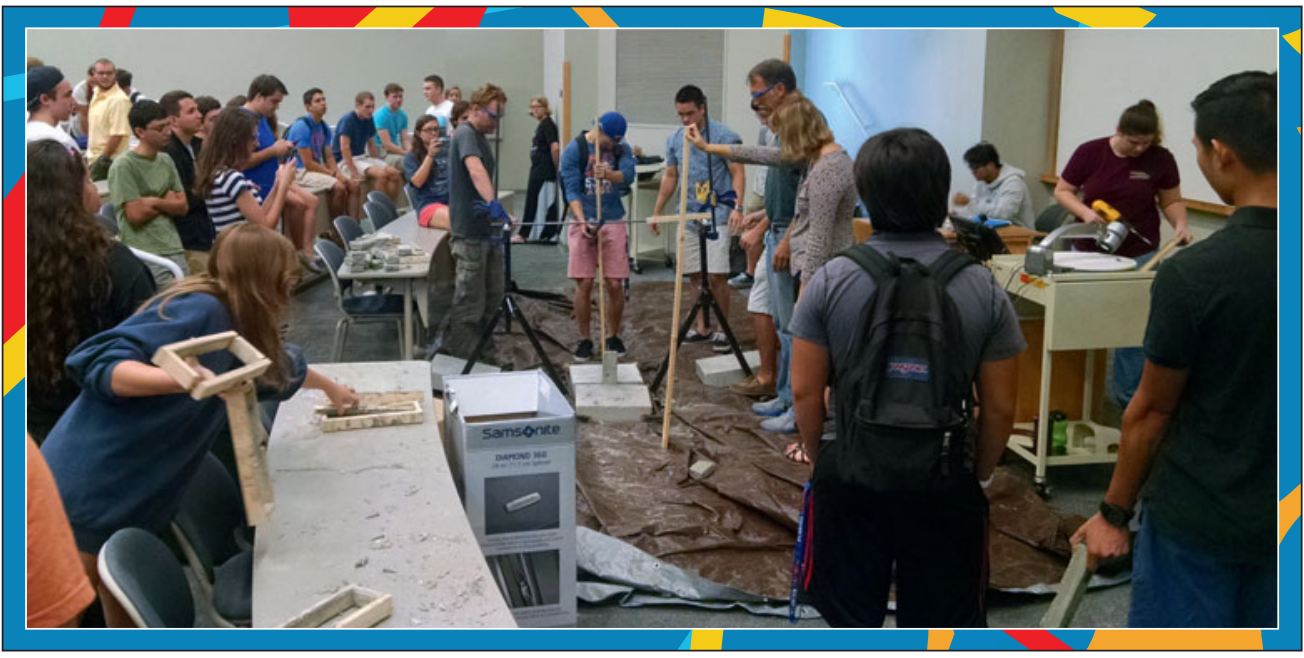

Professor Kevin Jones and student teams test the toughness of cement blocks during an IMOS class at the University of Florida. paradigms of different materials. In examining case studies from the past, students learn key lessons and principles to apply when thinking about the future social impacts of new materials and how engineers play important roles in changing or maintaining the structure and fabric of society. In the process, students take part in handson demos and activities to understand the properties and uses of new materials.

Each weekly unit has an accompanying video lesson that introduces the science behind recent materials innovations and asks students to imagine their future social impacts. The IMOS subcommittee has been critical in identifying the topics and scientists that were used for the making of these videos on materials innovations.

More than 40 community colleges, colleges, and universities have expressed an interest in teaching the course, including many institutions outside of the United States. After piloting the course for three semesters and growing it to over 200 students per year, the IMOS subcommittee and the University of Florida faculty have developed a public version of the curricular materials. All of the materials are available online. There has been strong support from various sources:

- The US Department of Defense funded digital curriculum materials, including an online course and instructor's guide, and 10 original videos on innovative materials research aligned with weekly modules.

- An open source e-textbook to enrich the humanities case studies was produced in partnership with Orange Grove Texts with support from the University of Florida Office of the Provost.

- MRS and the National Science Foundation supported workshops to help instructors learn how to teach the class. Some of the weekly units include information on

- concrete, smart materials and engineering society through social spaces;

- aluminum, amorphous metals, and intellectual property;

- iron, magnesium, and creative destruction;

- gold, silver, and the creation of value; and

- polymers, Tupperware, and materials marketing.

The course has come a long way since its inception, and the IMOS subcommittee is excited to offer a free IMOS Implementation Workshop on Tuesday, November 29, at the 2016 MRS Fall Meeting in Boston. This day-long training will facilitate the implementation of the course to interested universities and community colleges and teach them how to access all the materials they will need to teach the IMOS class. Please note: You do not need to be registered for the 2016 MRS Fall Meeting to attend the IMOS Implementation Workshop. However, preregistration for the workshop is suggested (www.mrs.org/imos-registration).

For additional information, visit www.mrs.org/imos. If you would like more information or think you might be interested in offering the class at your institution, please contact either Kevin Jones (kjones@eng.ufl.edu) or Pam Hupp (hupp@mrs.org). All materials are free, including the textbook.

The IMOS project was developed, in part, with the help of MRS staff and volunteers organized by the IMOS subcommittee (chaired by Kevin Jones) of the Public Outreach Committee (POC). The POC's mission is to advocate for and support materials science education outreach (EO) to the public at all science literacy levels and geographic scales (i.e., locally, nationally, and globally). The POC collaborates with individuals, educational organizations, companies, and government agencies to further this mission. In addition to external programming, the POC serves the members of MRS through presentation of a variety of professional development programs at MRS meetings and supports their EO efforts. Other subcommittees of POC include Strange Matter Green Earth (www.mrs. org/strange-matter-green-earth), Focus on Sustainability (www.mrs.org/sustainability), and Education Symposium Planning Subcommittees (www.mrs.org/ education-symposium-planning). 